\title{
Biostatistical Analysis on Fagopyrum Tataricum Gaertn
}

\author{
Bin Zhao ${ }^{1 *}$, Kuiyun Huang ${ }^{1}$, Xia Jiang ${ }^{2}$ and Jinming $\mathrm{Cao}^{3}$ \\ ${ }^{1}$ Department of Science, Hubei University of Technology, China \\ ${ }^{2}$ Hubei University of Technology, China \\ ${ }^{3}$ Department of Information and Mathematics, Yangtze University, China
}

*Corresponding author: Bin Zhao, School of Science, Hubei University of Technology,

Wuhan, Hubei, China.

Received Date: February 18, 2019

Published Date: March 01, 2019

\begin{abstract}
The effects of nitrogen application at different levels $(0,45,135$ and $225 \mathrm{~kg} / \mathrm{ha}$ in 2015 and 0, 90, 180, 270 kg/ha in 2017) on the physicochemical characteristics of Fagopyrum tataricum Gaertn starch were studied by field experiments. Starch from Fagopyrum tataricum Gaertn with application of nitrogen showed lower amylose content, particle size, and retrogradation, and higher structure complexity, pasting temperature, gelatinization enthalpy, relative crystallinity, light transmittance, solubility of the starch. Nitrogen application did not change the 'A'-type crystalline pattern of Fagopyrum tataricum Gaertn starch. This study indicated that nitrogen level and years and the interactions among nitrogen fertilizer levels and years significantly affected physicochemical properties of Fagopyrum tataricum Gaertn starch. The integrated results also provide some information into the management of the fertilization conditions to obtain starches with special properties for applications in food or non-food industries.
\end{abstract}

Keywords: Fagopyrum tataricum gaertn; Nitrogen; Starch properties

\section{Introduction}

Fagopyrum tataricum Gaertn (Tartary buckwheat) is an annual dicotyledonous pseudo cereal of the Polygonate family [1]. It can grow under low input conditions and be adapted to marginal lands with harsh environments [2], and it is cultivated mainly in southern China, northern India, Bhutan, and Nepal [4]. Fagopyrum tataricum Gaertn is one of the main minor grain crops and important medicinal crops rich in flavonoids over the world. Fagopyrum tataricum Gaertn has a great efficacy to reduce hypoglycemia hypolipidemic, even can be used to support the prevention and treatment of diabetes, high blood fat, hypertension and other diseases because of inutrientrich and it's rich in flavonoid. Nitrogen is an essential nutrient for Fagopyrum tataricum Gaertn due to its effects on the yield and quality of Fagopyrum tataricum Gaertn. Starch physicochemical characteristics represent the important parameters of Fagopyrum tataricum Gaertn quality.

Recently, Fagopyrum tataricum Gaertn is catching more attentions because it contains high nutritional content (e.g., antioxidants, protein, dietary fiber, and resistant starch) and disease-preventative roles [3]. Fagopyrum tataricum Gaertn can be used for the production of many products, such as noodles, breads, cakes, teas and alcoholic drink [6]. The starch is the major component of Fagopyrum tataricum Gaertn seed and its content is high and around 70\% [4]. Fagopyrum tataricum Gaertn starch had special physicochemical properties and is thereby capable of being exploited as a potential source of retrograded starch [5]. And it is also responsible for the textural properties of Fagopyrum tataricum Gaertn products in the absence of gluten protein [6]. Compared with wheat and corn starch, Fagopyrum tataricum Gaertn starch has a higher amylose content (20\%-28\%), a better water-binding capacity, more stable pasting properties, and lower percentage of retrogradation [7]. Fagopyrum tataricum Gaertn starch consists of amylopectin and amylose. The amylose content is one of most important traits to impact the quality of Fagopyrum tataricum Gaertn.

The structure and physicochemical properties of Fagopyrum tataricum Gaertn starch are affected by genetic background, soil conditions, climatic conditions and agricultural treatments during Fagopyrum tataricum Gaertn growth and development 
[8]. Nitrogen is an important and non-negligible environmental factor affecting crop quality. Many studies suggested that nitrogen fertilizer is not contributing to crop quality improvement, but many research results showed that appropriate nitrogen can maintain and improve crop quality $[9,10]$. Previous studies suggested that nitrogen fertilizer can significantly lower the peak viscosity, hot paste viscosity, cool paste viscosity, breakdown viscosity, amylose content and improve the physicochemical properties of rice starch $[11,12]$, and affect the biosynthesis and quality of barley starch [13]. However, the effects of nitrogen fertilizer on starch were mainly studied on maize [14], wheat [15] and barley [13], rice [16]. To the best of our knowledge, there are few reports on how nitrogen application affects the physicochemical properties of Fagopyrum tataricum Gaertn starch. Therefore, it is essential to compare the physicochemical characteristics of Fagopyrum tataricum Gaertn starch of varied levels of nitrogen application and to evaluate the most optimum amount of nitrogen fertilizer applied to achieve high quality for its potential use in the food and non-food industries.

\section{Material and Methods}

\section{Plant materials and experimental design}

Seeds of the variety No. 2019 of Fagopyrum tataricum Gaertn were collected in the test farm (109.7E, 38.3N, altitude $1080 \mathrm{~m}$ ), Yulin, Shaanxi Province, China. The soil type is sandy loam. The crop previous to Fagopyrum tataricum Gaertn was nursery. Soil had $0.15 \%$ total nitrogen, $1.82 \mathrm{mg} / \mathrm{kg}$ available phosphorus, and $21.65 \mathrm{mg} / \mathrm{kg}$ available potassium. These seed samples were grown under the same conditions. The meteorological data was offered by agricultural meteorological information service platform.

The experiment was arranged in a randomized block design. The nitrogen level included 0, 45, 135 and $225 \mathrm{~kg} / \mathrm{ha}$ in 2015 and 0, 90, 180, $270 \mathrm{~kg} / \mathrm{ha}$ in 2017 (non, low, medium and high nitrogen level). All the groups were treated with potassium (K) $37.5 \mathrm{~kg} / \mathrm{ha}$ and phosphorus (P) $37.5 \mathrm{~kg} / \mathrm{ha}$. Seeds were sown on July 10 and the harvest time was October 7. Nitrogen fertilizer was applied in the form of base fertilizer and then no longer topdressing during the growth of Fagopyrum tataricum Gaertn. Other practices were in conformity with local recommendations.

\section{Starch isolation}

Five hundred grams of the Fagopyrum tataricum Gaertn seeds of the different treatments were separately taken, ground with universal high speed smashing machines (FW100, Taisite LTD, Tianjin, China) and sieved with 200 mesh $(<75 \mu \mathrm{m})$ sieve to obtain Fagopyrum tataricum Gaertn flour. Fagopyrum tataricum Gaertn flour with $80 \%$ ethanol with the solid-liquid ratio of 1:20 was treated at $50{ }^{\circ} \mathrm{C}$ for $30 \mathrm{~min}$ by ultrasonic treatment at the power of $500 \mathrm{~W}$ to remove the flavonoids. Then add distilled water at the solid-liquid ratio of $1: 10(\mathrm{~g} / \mathrm{mL})$, and soak in a water bath at $30{ }^{\circ} \mathrm{C}$ for $18 \mathrm{~h}$ to remove protein. Let it stand for a few minutes and then pour off the upper suspension and place it in an oven at $40^{\circ} \mathrm{C}$. After removing the fat with petroleum ether, the excess petroleum ether was washed away with $80 \%$ ethanol and washed repeatedly with water. Centrifuged at $4000 \mathrm{r} / \mathrm{min}$ for $10 \mathrm{~min}$ and the supernatant was removed. The upper gray matter was scraped until only white material and the lower white material was poured in a Petri dish or beaker. Finally, the Fagopyrum tataricum Gaertn starch was dried in an oven at $40{ }^{\circ} \mathrm{C}$ for $24 \mathrm{~h}$ and sieved with 100 mesh $(<150 \mu \mathrm{m})$ sieve. The starch was sealed in self-sealing plastic bags and stored at $4{ }^{\circ} \mathrm{C}$ for use.

\section{Amylose content}

The amylose contents of the starches were measured and calculated according to the method of Yang and Zhang et al. [17]. The absorbance of the solutions of Fagopyrum tataricum Gaertn starches at different nitrogen levels was measured at 434 and 604 nm using the Blue Star B spectrophotometer (Saith Chemical Co., Ltd, Wuhan, China).

\section{Scanning electron microscopy (SEM) observation}

The starch samples were affixed to the loading platform of the surface processor using a double-sided adhesive tape, and then put into the processor. The surface morphology of starch granules was observed and then photographed using scanning electron microscopy (JSM-6360LV, Jeol, Japan). The magnification was $2000 \times$.

\section{Granule size analysis}

The granule size was carried out using a laser diffraction particle size analyzer (Mastersizer 2000E, Malvern, England). The starch was in tap water and stirred. The instrument could measure starch samples between 0.1 and $1000 \mu \mathrm{m}$.

\section{Bivariate flow cytometric analysis}

Starch granules were stained according to the method of Zhang, Feng et al. [18]. A bio fluorescent microscope (Imager M2, Carl Zeiss, Germany) was utilized to examine the starch staining efficiency. However, the starch suspension reagent was $\mathrm{ddH}_{2} \mathrm{O}$. The Fagopyrum tataricum Gaertn starch granule suspensions were measured using BD FACSAria ${ }^{\mathrm{TM}}$ III, BD, America and analyzed using BD Bioscience [18].

\section{Pasting properties}

Pasting properties of starch samples were determined using the Rapid Viscosity Analyzer (RVA4500, Parten, Stockholm, Sweden). Three grams of each sample with $14.0 \%$ moisture were directly weighed into aluminum RVA canisters, after which, $25.0 \mathrm{~mL}$ distilled water was added to achieve a total weight of $28.0 \mathrm{~g}$. The parameters were set: The slurry was held at $50{ }^{\circ} \mathrm{C}$ for $1 \mathrm{~min}$, then heated from $50{ }^{\circ} \mathrm{C}$ to $95^{\circ} \mathrm{C}$ for $3.7 \mathrm{~min}$, and held at $95^{\circ} \mathrm{C}$ for $2.5 \mathrm{~min}$. Finally, the sample was allowed to cool to $50^{\circ} \mathrm{C}$ for $3.8 \mathrm{~min}$ and held at $50{ }^{\circ} \mathrm{C}$ for $2 \mathrm{~min}$ [19].

\section{Thermal properties}

The thermal characteristics of the test starches were determined by a differential scanning calorimeter (DSC) (DSC2000, TA instrument, United States). The DSC analyzer was calibrated using indium. A total of $3.0 \mathrm{mg}$ of the dried starch sample was mixed 
with two times volume of water sealed in an aluminum pan at room temperature in 2 hours. The sample pans were heated to $110^{\circ} \mathrm{C}$ at a rate of $10^{\circ} \mathrm{C} / \mathrm{min}$, while one empty aluminum pan was used as the control. The starch gelatinization parameters that the DSC curve involved were onset temperature (To), completion temperature (Tc), peak temperature (Tp) and phase transition enthalpy $\Delta H$ [20].

\section{$\mathrm{X}$-ray diffraction analysis}

XRD patterns of samples were obtained on an X-ray diffractometer (D8 ADVANCE A25; Bruker, Germany). The starch samples were scanned at $4^{\circ}-60^{\circ}(2 \theta)$ and a rate of $8^{\circ} /$ min at a target voltage of $40 \mathrm{kV}$ and a current of $40 \mathrm{~mA} \mathrm{[5].} \mathrm{Relative} \mathrm{crystallinity}$ (\%) was calculated by using software (MDI Jade 6).

\section{Retrogradation}

One percent starch pastes of the samples were prepared and placed into $20 \mathrm{~mL}$ graduated test tubes with stopper, $20 \mathrm{~mL}$ per tube, and stored at $25{ }^{\circ} \mathrm{C}$ for $24 \mathrm{~h}$. During this storage period, the supernatant volumes of the tubes were counted every hour. Accordingly, the retrogradation curve of the supernatant volume percentages with time was drawn [21].

\section{Light transmittance}

The light transmittance was measured according to Chao et al. [21] with the Blue Star B spectrophotometer (Lab tech Ltd, Beijing, China) using distill water as their control.

\section{Solubility}

The solubility of the starch samples was determined by using the method described by Chao et al. and Liu et al. [22,23]. Each $200 \mathrm{mg}$ starch sample was transferred to a dry centrifugal tube, weighed, and mixed with $10 \mathrm{~mL}$ distilled water. Each tube was incubated in a shaking water bath at $60,70,80$, and $90^{\circ} \mathrm{C}$ for $30 \mathrm{~min}$, cooled to room temperature, and centrifuged at $2000 \mathrm{r} / \mathrm{min}$ for 20 min. The supernatant was carefully decanted, and the tube with the remaining contents was weighed. The residue obtained after drying the supernatant represents the amount of starch dissolved in water. The solubility of the samples was calculated on a dry-weight basis (DB) through the following equation:

Solubility = the weight of dried supernatant weight of starch

\section{Data processing}

All the tests and measurements were repeated trice and the data thus obtained were statistically analyzed by SPSS 19.0 (SPSS Inc., Chicago, IL, USA). All data represent the mean \pm standard deviation. Difference significances among the means were tested by the analysis of variance and the least significant difference (LSD) at $\mathrm{p}<0.05$.

\section{Results and Discussion}

\section{The temperature variation of fagopyrum tataricum Gaertn during grain-filling stage}

Grain-filling stage is the key period of dry matter and starch accumulation and the temperature is an important parameter that affects the crop growth and development [24]. Fagopyrum tataricum Gaertn began to produce more grains at about 40 days after seeding emergence and there were an end of filling stage at around 80 days for most of the Fagopyrum tataricum Gaertn grains [25]. Therefore, the date from 40 to 80 days after emergence was selected in order to investigate the effect of temperature change on amylose accumulation and starch characteristics. Compared with the maximum temperature in 2017 from 40 to 57 days, the higher maximum temperature and minimum temperature in 2015 could be seen in in the Figure $1 \mathrm{~A}$ and the similar trend can also be observed at mean temperature (Figure 1C). As shown in the Figure.

$1 \mathrm{~B}$, there were a lower temperature difference from 40 to 50 days and a higher temperature difference from 50 to 80 days in 2017. Zhang et al. reported that the content of starch and amylose and the activities of key enzymes involved in starch synthetic metabolism in developing rice grains were influenced by different temperatures during grain filling stage [26]. And some studies indicated that heat stress during grain filling generally decreases starch contents and enlarges starch granules [27]. High temperature during early grain development play a more important role in affecting the starch pasting properties, crystalline structure, and granule size of cereal starches than that during late grain development [28].

\section{Amylose content}

The amylose content of starches ranged from $25.26 \%$ to $28.61 \%$ and differed significantly among different treatments (Table 1) (Figure 1).

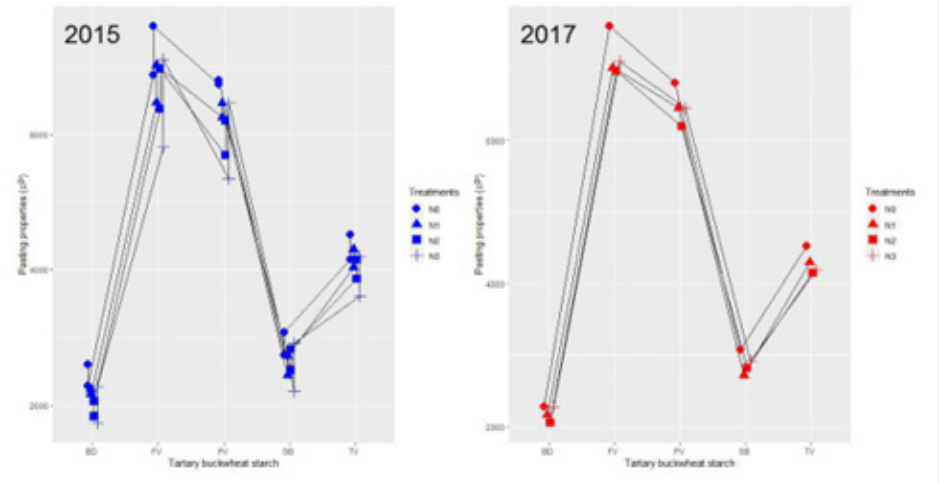

Figure 1: Effect of different nitrogen levels on the amylose content and pasting properties of Fagopyrum tataricum Gaertn starch.s 
Table 1: Effect of different nitrogen levels on the amylose content and pasting properties of Fagopyrum tataricum Gaertn starch.

\begin{tabular}{|c|c|c|c|c|c|c|c|c|}
\hline \multirow{2}{*}{ Year } & \multirow{2}{*}{ Treatments } & \multirow{2}{*}{$\begin{array}{c}\text { Amylose } \\
\text { content (\%) }\end{array}$} & \multicolumn{6}{|c|}{ Pasting properties } \\
\hline & & & $\mathrm{PV}(\mathrm{cP})$ & $\mathrm{TV}(\mathrm{cP})$ & $\mathrm{BD}(\mathrm{cP})$ & $\mathrm{FV}(\mathrm{cP})$ & $\mathrm{SB}(\mathrm{cP})$ & Ptemp $\left({ }^{\circ} \mathrm{C}\right)$ \\
\hline \multirow[t]{4}{*}{2015} & No & $28.56 \pm 0.23 a$ & $6744 \pm 81 a$ & $4149 \pm 28 \mathrm{a}$ & $2595 \pm 29 a$ & $6885 \pm 49 a$ & $2736 \pm 53 a$ & $73.90 \pm 0.60 \mathrm{~d}$ \\
\hline & $\mathrm{N} 1$ & $26.77 \pm 0.12 b$ & $6258 \pm 56 b$ & $4033 \pm 42 \mathrm{ab}$ & $2226 \pm 45 b$ & $6471 \pm 102 b$ & $2439 \pm 46 b$ & $73.95 \pm 0.70 \mathrm{c}$ \\
\hline & N2 & $26.37 \pm 0.09 c$ & $5697 \pm 52 c$ & $3864 \pm 47 b$ & $1833 \pm 37 \mathrm{c}$ & $6380 \pm 77 b$ & $2516 \pm 48 b$ & $74.35 \pm 0.30 \mathrm{~b}$ \\
\hline & N3 & $25.35 \pm 0.11 \mathrm{~d}$ & $5347 \pm 34 d$ & $3612 \pm 29 \mathrm{c}$ & $1735 \pm 32 d$ & $5816 \pm 83 c$ & $2204 \pm 64 c$ & $74.75 \pm 0.10 \mathrm{a}$ \\
\hline \multirow[t]{4}{*}{2017} & No & $28.61 \pm 0.15 \mathrm{a}$ & $6807 \pm 68 a$ & $4522 \pm 36 a$ & $2285 \pm 28 a$ & $7600 \pm 64 a$ & $3078 \pm 37 a$ & $74.25 \pm 0.30 \mathrm{c}$ \\
\hline & N1 & $27.2 \pm 0.21 b$ & $6465 \pm 43 b$ & $4301 \pm 50 \mathrm{~b}$ & $2164 \pm 23 c$ & $7022 \pm 51 \mathrm{c}$ & $2721 \pm 36 \mathrm{~d}$ & $74.30 \pm 0.10 \mathrm{~b}$ \\
\hline & N2 & $25.26 \pm 0.32 d$ & $6204 \pm 36 c$ & $4150 \pm 35 d$ & $2054 \pm 40 \mathrm{~d}$ & $6976 \pm 92 \mathrm{~d}$ & $2826 \pm 21 b$ & $74.35 \pm 0.80 \mathrm{a}$ \\
\hline & N3 & $26.49 \pm 0.18 c$ & $6463 \pm 74 b$ & $4192 \pm 48 c$ & $2271 \pm 31 b$ & $7109 \pm 69 b$ & $2917 \pm 55 b$ & $74.35 \pm 0.60 \mathrm{a}$ \\
\hline
\end{tabular}

Note: Different letters within a column indicate significant difference among mean values $(p<0.05)$. PV: peak viscosity; TV : trough viscosity; BD: breakdown viscosity; FV: final viscosity; SB: setback viscosity; Ptemp: pasting temperature

The amylose content of the starch decreased gradually in 2015 and decreased at first and then increased in 2017 with increasing nitrogen level. The lowest amylose content of $25.26 \%$ was observed at $\mathrm{N}_{2}$ treatment (180 kg/ha) and the highest of $28.61 \%$ at $\mathrm{N} 0$ treatment $(0 \mathrm{~kg} / \mathrm{ha})$ in 2017 . Kossmann et al. reported that the activities of soluble starch synthase (SSS) and starch branching enzymes (SBE) involved in the biosynthesis of branched components within the starch granule may affect the amylose content of the different starch fractions [29]. The reduction in the amylose content of Fagopyrum tataricum Gaertn starch may be attribute to the increase of the activities of SSS and SBE with increasing $\mathrm{N}$ level. This result was consistent with the report of Singh, Pal, Mahajan, and Shevkani [12]. What is more, the storage of Wx proteins had been reported to be increased at lower temperatures, which may lead to a higher amylose content in Fagopyrum tataricum Gaertn starch in 2017 [30]. Amylose content plays a key role in the digestion of starches, as starches with low amylose content digests easily than that of high amylose content [31].

\section{Starch granule morphology of fagopyrum tataricum Gaertn}

The starch granule morphology of Fagopyrum tataricum Gaertn using different nitrogen fertilizer was examined using SEM. The granules showed polygonal shapes with smooth edges and spherical shapes (Figure2), similar to the finding of Gao et al. using common buckwheat starch [5]. The shapes of starch granule morphology after different treatments were not altered. However, several striking differences were observed between the different treatments. For example, the large starch granules and the proportion of large starch granules at N0 and N1 treatments were bigger than that of N2 and N3 treatments. The similar results also were found in rice starch [16].

\section{Starch particle size distribution}

The size distribution of Fagopyrum tataricum Gaertn starch granules was observed and the differences under different nitrogen levels were significant (Table 2) (Figure 2).

Table 2: Effects of different nitrogen levels on the granule size distribution of Fagopyrum tataricum Gaertn starch.

\begin{tabular}{|c|c|c|c|c|}
\hline \multirow{2}{*}{ Year } & \multirow{2}{*}{ Treatments } & \multicolumn{3}{|c|}{ Diameter of starch granule $/ \mu \mathrm{m}$} \\
\cline { 2 - 5 } & & $<5$ & $5-15$ & $>15$ \\
\hline \multirow{3}{*}{2015} & $\mathrm{~N} 0$ & $2.52 \pm 0.07 \mathrm{c}$ & $81.97 \pm 0.13 \mathrm{c}$ & $15.51 \pm 0.12 \mathrm{a}$ \\
\cline { 2 - 5 } & $\mathrm{N} 1$ & $2.70 \pm 0.11 \mathrm{bc}$ & $92.45 \pm 0.15 \mathrm{~b}$ & $4.85 \pm 0.21 \mathrm{~b}$ \\
\cline { 2 - 5 } & $\mathrm{N} 2$ & $2.85 \pm 0.17 \mathrm{~b}$ & $92.69 \pm 0.06 \mathrm{~b}$ & $4.46 \pm 0.17 \mathrm{c}$ \\
\cline { 2 - 5 } & $\mathrm{N} 3$ & $3.14 \pm 0.04 \mathrm{a}$ & $95.47 \pm 0.04 \mathrm{a}$ & $1.39 \pm 0.15 \mathrm{~d}$ \\
\hline \multirow{3}{*}{2017} & $\mathrm{~N} 0$ & $3.65 \pm 0.02 \mathrm{~d}$ & $72.70 \pm 0.08 \mathrm{c}$ & $23.65 \pm 0.14 \mathrm{a}$ \\
\cline { 2 - 5 } & $\mathrm{N} 1$ & $4.06 \pm 0.05 \mathrm{c}$ & $75.70 \pm 0.06 \mathrm{~b}$ & $20.24 \pm 0.02 \mathrm{~b}$ \\
\cline { 2 - 5 } & $\mathrm{N} 2$ & $4.53 \pm 0.03 \mathrm{~b}$ & $76.27 \pm 0.04 \mathrm{a}$ & $19.20 \pm 0.05 \mathrm{c}$ \\
\cline { 2 - 5 } & $\mathrm{N} 3$ & $7.29 \pm 0.12 \mathrm{a}$ & $76.30 \pm 0.12 \mathrm{a}$ & $16.41 \pm 0.08 \mathrm{~d}$ \\
\hline
\end{tabular}

Note: Different letters within a column indicate significant difference among mean values $(p<0.05)$.
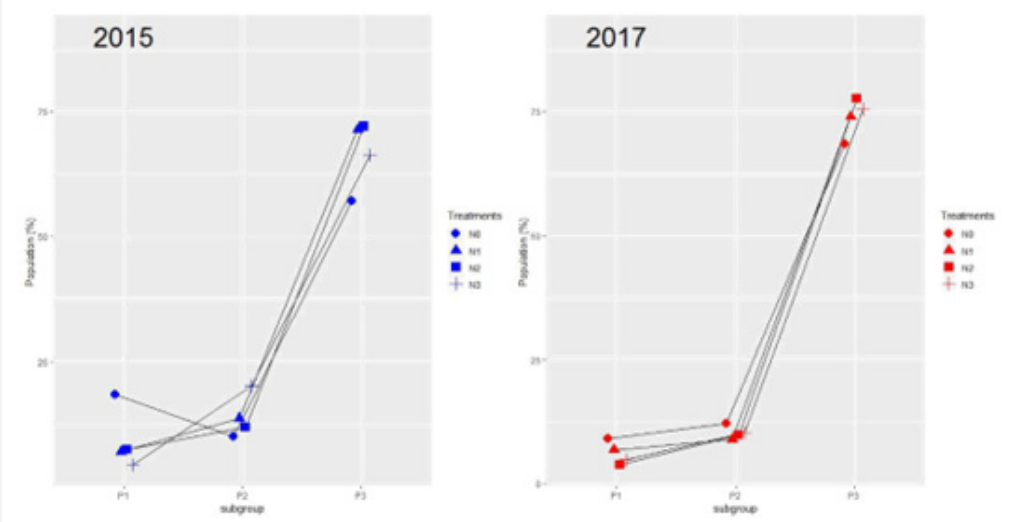

Figure 2: Effects of different nitrogen levels on the granule size distribution of Fagopyrum tataricum Gaertn starch. 
Granule size distribution was classified into A- (> $15 \mu \mathrm{m})$, B(5-15 $\mu \mathrm{m})$, and C-granules $(<5 \mu \mathrm{m})$ [32]. Among all the starches, B-granules had the highest contribution to the total volume (72.70\%-95.47\%), followed by A- (1.39\%-23.65\%) and C-granules (2.52\%-7.29\%). Starches under N3 treatment showed the highest proportion of B- and C-granules and the lowest proportion of A-granules, while starches under N0 treatment showed the lowest proportion of $\mathrm{B}$ - and C-granules and the highest proportion of A-granules (Table 2), which is consistent with the starch granule morphology using SEM. Previous reports have shown that the big starch granules usually developed at early stage while small starch granules appeared at late growth stages and had a low amylose content [33]. However, Sing et al. indicated that amylose did not show any correlation with the proportion of A-, B-, and C-granules [34]. In this study, the proportion of granule C-granules decreased with increasing nitrogen level, which was nearly conformity with the decrease of amylose content. The cause may be that increased nitrogen application have extended the duration of grain filling, in which big starch granules could be decomposed into small and medium granules [33]. In addition, with increasing nitrogen level, the SSS and SBE activities increased, which was thought to be the reason of the increase of the synthesis of amylopectin and the amount of small-size starch granules during late growth stages [35]. The present result was in conformity with the finding of Zhu \& Zhang [16]. The lower proportion of granule C-granules in 2015 than that in 2017 may be the reason that the higher temperature during the early grain filling stage in 2015 inactivates specific biosynthetic enzymes and restrains the production of small granules [36].

\section{Bivariate flow cytometric analysis}

As shown in the data above, the Fagopyrum tataricum Gaertn starch granule suspensions were analyzed biparametrically and plots of side-scattered light (SSC) versus forward-scattered light (FSC) and side-scattered light (SSC) versus fluorescein isothiocyanate (FITC) were created to reflect the characteristics of the starch granules. Specifically, SSC versus FSC histograms represent the classification of starch granules considering granule size and integral structure complexity. FSC versus FITC refers to the particle features of granule size and internal structure. Fagopyrum tataricum Gaertn starches under different nitrogen levels all were composed of three subgroups, P1, P2, and P3. The fluorescence imaging and the fluorescence intensity image indicated that starch granules were stained by APTS compared with the negative control, where P3 consisted of the highest fluorescence intensity starch particles, followed by the starch particles of P2 and P1. P1 consisted of the smallest and least complex starch particles, P2 consisted of starch granules with medium size and complexity and P3 consisted mainly of starch granules with maximum size and complexity. The results indicated that nitrogen application did not change the number of subgroups but change the proportion of every subgroup (Table 3) (Figure 3)

Table 3: Effects of different nitrogen levels on the proportion of starch granules subgroups.

\begin{tabular}{|c|c|c|c|c|}
\hline \multirow{2}{*}{ Year } & \multirow{2}{*}{ Treatments } & \multicolumn{3}{|c|}{ Population(\%) } \\
\cline { 3 - 5 } & & P1 & P2 & P3 \\
\hline \multirow{3}{*}{2015} & N0 & $18.40 \mathrm{a}$ & $10.10 \mathrm{~d}$ & $57.20 \mathrm{~d}$ \\
\cline { 2 - 5 } & $\mathrm{N} 1$ & $7.00 \mathrm{~b}$ & $13.70 \mathrm{~b}$ & $71.40 \mathrm{~b}$ \\
\cline { 2 - 5 } & $\mathrm{N} 2$ & $7.50 \mathrm{~b}$ & $12.00 \mathrm{c}$ & $72.10 \mathrm{a}$ \\
\cline { 2 - 5 } & $\mathrm{N} 3$ & $4.40 \mathrm{c}$ & $20.20 \mathrm{a}$ & $66.30 \mathrm{c}$ \\
\hline \multirow{3}{*}{2017} & $\mathrm{~N} 0$ & $9.10 \mathrm{a}$ & $12.20 \mathrm{a}$ & $68.40 \mathrm{~d}$ \\
\cline { 2 - 5 } & $\mathrm{N} 1$ & $6.80 \mathrm{~b}$ & $8.90 \mathrm{c}$ & $73.90 \mathrm{c}$ \\
\cline { 2 - 5 } & $\mathrm{N} 2$ & $3.80 \mathrm{~d}$ & $9.80 \mathrm{~b}$ & $77.60 \mathrm{a}$ \\
\cline { 2 - 5 } & $\mathrm{N} 3$ & $4.80 \mathrm{c}$ & $10.30 \mathrm{~b}$ & $75.40 \mathrm{~b}$ \\
\hline
\end{tabular}

Note: Different letters within a column indicate significant difference among mean values $(p<0.05)$.
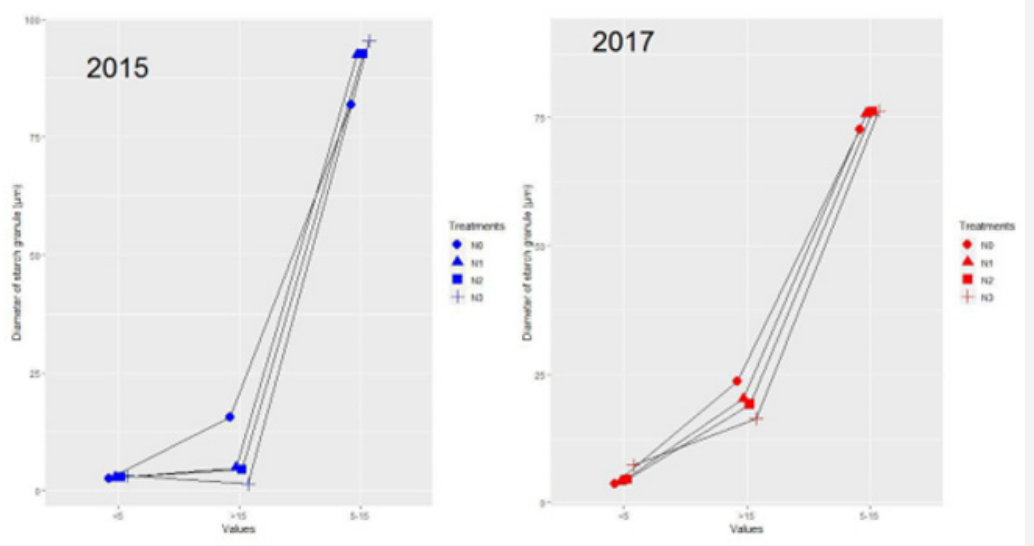

Figure 3: Effects of different nitrogen levels on the proportion of starch granules subgroups.

With increasing level, the proportion of P1 subgroup decreased while the proportion of P3 increased at first and then decreased. The fluorescence intensity of the P1 subgroup was weaker, probably because the proportion of the P1 subgroup was lower and the starch granules were lower in size and complexity, which may lead to the starch particles of P1 subgroup with the combined fluorescent dyes were fewer.

\section{Pasting properties}

Pasting properties of starch showed significant variation under different nitrogen levels (Table 1). With increasing nitrogen level, 
peak viscosity, trough viscosity, breakdown viscosity, setback viscosity and final viscosity decreased, and pasting temperature increased. Peak viscosity is the maximum viscosity attained by gelatinized starch during heating in water, reflecting the water binding capacity of the starch granule and the extend of swelling of starch granules [37]. The differences of peak viscosity could be due to variation in the rate of water absorption and swelling of starch granules during heating. Pasting temperature is the temperature when the viscosity begins to increase during the heating process [37]. Low breakdown viscosity value means high ability to resist heating [38]. Final viscosity contributes stability and rigidity to the swollen granule structure, leading to a higher ultimate paste viscosity.

The starch pastes under N3 treatment (225kg/ha) in 2015 and $\mathrm{N}_{2}$ treatment (180kg/ha) in 2017 had lower viscosities. The reason may be that larger granules possess a loose packing ability and occupy a relatively larger volume, and starch rheology is mainly influenced by particle size [39]. Hence, the suspensions (N0) of large size particles tend to be more viscous compared to those (N3 in 2015 and $\mathrm{N}_{2}$ in 2017) of the counterpart smaller size. The present result was in conformity with the finding of Zhu et al. [40] that rice flour had a lower peak viscosity under high nitrogen level. Setback viscosity reflected the recovery of the viscosity of the heated starch paste and was caused by leached amylose rearrangement during cooling [41]. Lower setback of the starch under the $\mathrm{N}_{3}$ in 2015 and $\mathrm{N}_{2}$ in 2017 may be due to the amount and the molecular weight of the amylose leached from the granules and the remnants of the gelatinized starch [42]. Final viscosity increased upon cooling may be due to the aggregation of the amylose molecules [43]. With increasing nitrogen level, the pasting temperature of Fagopyrum tataricum Gaertn starch increased $(\mathrm{p}<0.05)$, which shows that nitrogen application significantly improved the thermal stability of Fagopyrum tataricum Gaertn starch and made it more difficult to gelatinize [44]. Pasting properties of starch has been reported to be affected by concentration of starch, amylose, and branching architecture of amylopectin, the ratio of amylose/amylopectin, granule size, and the presence of lipids that can complex with amylose [34].

\section{Thermal properties}

Thermal properties (onset temperature, To; peak temperature, $\mathrm{Tp}$; endset temperature, Tc; and enthalpy of gelatinization, $\Delta \mathrm{H}$ ) of starch under different nitrogen treatments are shown in (Table 4) (Figure 4).

Table 4: Effect of different nitrogen levels on thermal properties and relative crystallinity.

\begin{tabular}{|c|c|c|c|c|c|c|}
\hline \multirow{2}{*}{ Year } & \multirow{2}{*}{ Treatments } & \multicolumn{4}{|c|}{ Thermal properties } & \multirow{2}{*}{ Relative crystallinity (\%) } \\
\hline & & To $\left({ }^{\circ} \mathrm{C}\right)$ & $\mathrm{Tp}\left({ }^{\circ} \mathrm{C}\right)$ & $\operatorname{Tc}\left({ }^{\circ} \mathrm{C}\right)$ & $\Delta \mathrm{H}(\mathrm{J} / \mathrm{g})$ & \\
\hline \multirow[t]{4}{*}{2015} & No & $65.24 \pm 0.01 \mathrm{a}$ & $68.51 \pm 0.03 \mathrm{~b}$ & $72.56 \pm 0.06 \mathrm{c}$ & $5.37 \pm 0.21 \mathrm{c}$ & $26.04 \pm 0.2 c$ \\
\hline & N1 & $64.84 \pm 0.37 \mathrm{ab}$ & $68.34 \pm 0.03 b$ & $72.56 \pm 0.04 c$ & $6.21 \pm 0.43 \mathrm{bc}$ & $27.81 \pm 0.1 \mathrm{~b}$ \\
\hline & $\mathrm{N} 2$ & $65.46 \pm 0.37 \mathrm{a}$ & $68.76 \pm 0.13 a$ & $73.14 \pm 0.04 \mathrm{~b}$ & $6.46 \pm 0.38 \mathrm{~b}$ & $28.18 \pm 0.3 \mathrm{~b}$ \\
\hline & N3 & $64.44 \pm 0.06 \mathrm{~b}$ & $68.46 \pm 0.03 \mathrm{~b}$ & $74.44 \pm 0.10 \mathrm{a}$ & $10.07 \pm 0.32 \mathrm{a}$ & $30.84 \pm 0.2 \mathrm{a}$ \\
\hline \multirow[t]{4}{*}{2017} & N0 & $66.95 \pm 0.08 \mathrm{~b}$ & $69.61 \pm 0.06 \mathrm{~b}$ & $73.45 \pm 0.40 \mathrm{~b}$ & $7.94 \pm 0.12 \mathrm{~b}$ & $29.91 \pm 0.2 \mathrm{~d}$ \\
\hline & $\mathrm{N} 1$ & $66.44 \pm 0.06 \mathrm{c}$ & $69.53 \pm 0.09 \mathrm{~b}$ & $74.51 \pm 0.04 \mathrm{a}$ & $9.37 \pm 0.17 \mathrm{a}$ & $31.72 \pm 0.1 \mathrm{c}$ \\
\hline & $\mathrm{N} 2$ & $67.00 \pm 0.08 \mathrm{~b}$ & $70.04 \pm 0.12 \mathrm{a}$ & $74.65 \pm 0.59 \mathrm{a}$ & $9.95 \pm 0.60 \mathrm{a}$ & $33.53 \pm 0.3 \mathrm{a}$ \\
\hline & N3 & $67.56 \pm 0.08 \mathrm{a}$ & $70.21 \pm 0.16 \mathrm{a}$ & $74.46 \pm 0.26 \mathrm{a}$ & $9.40 \pm 0.15 \mathrm{a}$ & $32.32 \pm 0.2 \mathrm{~b}$ \\
\hline
\end{tabular}

Note: Different letters within a column indicate significant difference among mean values $(p<0.05)$.
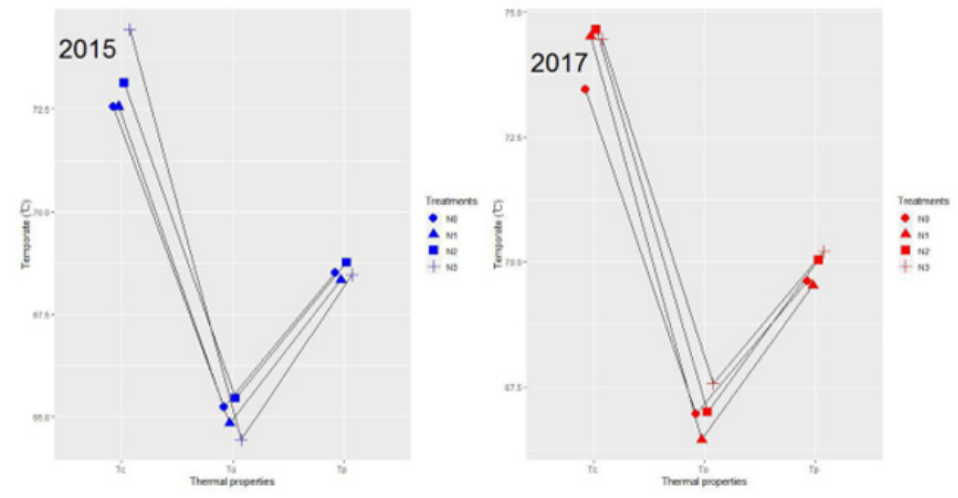

Figure 4: Effect of different nitrogen levels on thermal properties and relative crystallinity

With the increase of nitrogen application, the gelatinization temperature and $\Delta \mathrm{H}$ increased significantly. The results were consistent with those obtained from RVA (Table 1). Gelatinization enthalpy $(\Delta \mathrm{H})$ was used to study starch crystalline structure and relative crystallinity [45]. The results were in agreement with those obtained from XRD, which reveals that the starch with a high $\Delta \mathrm{H}$ at the high nitrogen level had a high relative crystallinity [46]. The difference of gelatinization temperatures might result 
from the different starch granule sizes at different nitrogen levels, amylose content, and amylopectin fine structure [47]. The amylose can restrict the hydration of amorphous regions, hinder the gelatinization of crystallinity, and raise the gelatinization temperature [48], and the starch with large size of starch granule has high gelatinization temperature [34]. However, in this study, the gelatinization temperature of the starches showed an increase with decreasing granule size and amylose content. The gelatinization properties may be influenced by other significant differences, such as their shape distribution, amylopectin molecular weight distribution, and branch chain length distribution of amylopectin, rather than amylose contents of starches [45].

\section{XRD and relative crystallinity}

The X-ray diff raction patterns of Fagopyrum tataricum Gaertn starch samples obtained under different nitrogen levels are presented in Figure 4. Generally, natural starches can be divided into A-, B- and C-type according to their XRD patterns [49]. The starch samples presented strong peaks at $15.03^{\circ}, 17.07^{\circ}, 17.96^{\circ}$ and $22.78^{\circ} 2 \theta$. The resulting X-ray diffraction patterns of the Fagopyrum tataricum Gaertn starch all presented the "A" type pattern, which indicated different $\mathrm{N}$ levels did not change the X-ray diffraction pattern. However, with increasing $\mathrm{N}$ level, the relative crystallinity increased as shown in the Table 1 , which are similar to the findings that relative crystallinity is negatively correlated to amylose content [16]. In addition, the variance of the relative crystallinity in 2015 and 2017 may affected by the different temperature at early development stage [24].

\section{Retrogradation}

The starch paste retrogradation percentages of the samples are shown in Figure. All the starch pastes had higher retrogradation rates during the initial $10 \mathrm{~h}$ standing. After 10-20 h standing, the starch paste retrogradation of Fagopyrum tataricum Gaertn under N3 treatment (225 kg/ha) in 2015 and N2 treatment (180 kg/ha) in 2017 gradually slowed down, and tended to stabilize after 20 h, with their average retrogradation percentage reaching $55.0 \%$, which were obviously lower than those of Fagopyrum tataricum Gaertn under other treatments. The different retrogradation percentages probably attributed to the differences of their amylose contents caused by different nitrogen levels, which implicated that nitrogen fertilizer application may be helpful to restrain starch retrogradation. It is worth noting that high retrogradation can cause the great changes on the mechanical properties of starch foods, such as decreasing the digestive characteristics of starch and increasing the hardness, thus affecting their nutritional values and sensory qualities $[21,50,51]$. The retrogradation of starch was also affected by starch structure, hot processing conditions, moisture content, and pasting temperature [52].

\section{Light transmittance}

With increasing nitrogen fertilizer application, the transparency of Fagopyrum tataricum Gaertn starch pastes significantly increased in 2015 and increased at first and then decreased in 2017 (Figure). The starch light transmittance under N3 treatment (225 kg/ha) averaged $34.7 \%$ and was higher than the starch light transmittance under other treatments in 2015. Fagopyrum tataricum Gaertn under N2 treatment (180 kg/ha) had the highest starch transmittance of $30.6 \%$ in 2017 . Starch paste transparency is affected by many factors, such as amylose content of starch, starch granule size and amylose/amylopectin ratio. This result was consistent with previous report that amylose content was negatively correlated with starch paste transparency [53]. And the difference of temperature during grain development in 2015 and 2017 may affect the amylose content and further result in the variance in the transparency.

\section{Starch solubility}

The solubility of Fagopyrum tataricum Gaertn starch increased with increasing temperature. The solubility of all samples increased from $60{ }^{\circ} \mathrm{C}$ to $90^{\circ} \mathrm{C}$. As shown in Figure, the starch solubility of all treatments ranged within $3.0 \%-11.7 \%$ at $60{ }^{\circ} \mathrm{C}, 4.2 \%-5.9 \%$ at $70{ }^{\circ} \mathrm{C}$, $7.7 \%-10.9 \%$ at $80{ }^{\circ} \mathrm{C}$ and $9.9 \%-12.1 \%$ at $90{ }^{\circ} \mathrm{C}$. Solubility indicates the ability of solids to dissolve or disperse in an aqueous solution (mostly water) [54]. The solubility of starch under the $\mathrm{N}_{3}$ treatment (225 kg/ha) from $60^{\circ} \mathrm{C}$ from $70^{\circ} \mathrm{C}$ in 2015 was the highest. In 2017 , the starch under the $\mathrm{N}_{2}$ treatment $(180 \mathrm{~kg} / \mathrm{ha})$ from $60^{\circ} \mathrm{C}$ from $70^{\circ} \mathrm{C}$ possessed the highest solubility. Higher solubility at high nitrogen level were attributed to higher water affinity of small granules at high nitrogen level as compared with large ones [55]. In addition, lower amylose content may lead to the increase of the solubility, as amylose can restrain further swelling and help maintain the structure of swollen starch granules. And the difference in solubility in two years may be relevant to the granule size distribution and amylose content affected by the temperature during filling stage.

\section{The effect of nitrogen fertilizer levels and years on the properties of starch}

Table 5: Effect of different nitrogen levels and years on physicochemical properties of Fagopyrum tataricum Gaertn starch.

\begin{tabular}{|c|c|c|c|c|}
\hline \multicolumn{2}{|c|}{ Variation } & Treatments & Years & Treatments $\times$ Years \\
\hline \multicolumn{2}{|c|}{ DF } & 3 & 1 & 3 \\
\hline \multirow{2}{*}{ Amylose content (\%) } & $182.1^{* *}$ & 1.8 & $24.3^{* *}$ \\
\hline \multirow{3}{*}{$\begin{array}{c}\text { Granule size distribution } \\
(\%)\end{array}$} & $<5(\mu \mathrm{m})$ & $432.5^{* *}$ & $2082.8^{* *}$ & $234.9^{* *}$ \\
\cline { 2 - 5 } & $5-15(\mu \mathrm{m})$ & $6676.0^{* *}$ & $108606.4^{* *}$ & $2085.0^{* *}$ \\
\hline \multirow{2}{*}{\begin{tabular}{c} 
Pasting properties \\
\cline { 2 - 5 }
\end{tabular}} & $>15(\mu \mathrm{m})$ & $4672.3^{* *}$ & $40453.3^{* *}$ & $684.2^{* *}$ \\
\cline { 2 - 5 } & $\mathrm{PV}(\mathrm{cP})$ & $200.7^{* *}$ & $271.4^{* *}$ & $66.0^{* *}$ \\
\hline
\end{tabular}




\begin{tabular}{|c|c|c|c|c|}
\hline & $\mathrm{BD}(\mathrm{cP})$ & $174.2^{* *}$ & $32.4^{* *}$ & $115.6^{* *}$ \\
\hline & $\mathrm{FV}(\mathrm{cP})$ & $76.4^{* *}$ & $437.1^{* *}$ & $20.8^{* *}$ \\
\hline & $\mathrm{SB}(\mathrm{cP})$ & $46.0^{* *}$ & $308.2^{* *}$ & $18.5^{* *}$ \\
\hline & Ptemp $\left({ }^{\circ} \mathrm{C}\right)$ & 0.8 & 0.1 & 0.5 \\
\hline \multirow{4}{*}{ Thermal properties } & To $\left({ }^{\circ} \mathrm{C}\right)$ & $6.7^{*}$ & $419.5^{* *}$ & $15.2^{* *}$ \\
\hline & $\mathrm{Tp}\left({ }^{\circ} \mathrm{C}\right)$ & $21.5^{* *}$ & $769.6^{* *}$ & $9.1^{* *}$ \\
\hline & $\operatorname{Tc}\left({ }^{\circ} \mathrm{C}\right)$ & $20.0^{* *}$ & $64.0^{* *}$ & $9.5^{* *}$ \\
\hline & $\Delta \mathrm{H}(\mathrm{J} / \mathrm{g})$ & $58.0^{* *}$ & $162.9^{* *}$ & $32.6^{* *}$ \\
\hline \multicolumn{2}{|c|}{ Relative crystallinity (\%) } & $213.9^{* *}$ & $1169.3^{* *}$ & $56.6^{* *}$ \\
\hline \multicolumn{2}{|c|}{ Transparency (\%) } & $245.7^{* *}$ & $44.3^{* *}$ & $162.8^{* *}$ \\
\hline \multirow{4}{*}{ Solubility } & $60\left({ }^{\circ} \mathrm{C}\right)$ & $239.3^{* *}$ & $410.2^{* *}$ & $19.7^{* *}$ \\
\hline & $70\left({ }^{\circ} \mathrm{C}\right)$ & $24.6^{* *}$ & $96.3^{* *}$ & $88.4^{* *}$ \\
\hline & $80\left({ }^{\circ} \mathrm{C}\right)$ & $23.0^{* *}$ & $77.5^{* *}$ & $40.3^{* *}$ \\
\hline & $90\left({ }^{\circ} \mathrm{C}\right)$ & $290.5^{* *}$ & $95.3^{* *}$ & $21.1^{* *}$ \\
\hline
\end{tabular}

Note: “*” indicate statistical differences at $\mathrm{p}<0.05$, “**” indicate statistical differences at $\mathrm{p}<0.01$. PV: peak viscosity; TV: trough viscosity; BD: breakdown viscosity; FV: final viscosity; SB: setback viscosity; Ptemp: pasting temperature; To: onset temperature; Tp: peak temperature; Tc: endset temperature; $\Delta \mathrm{H}$ : enthalpy of gelatinization.

The result of analysis of variance showed that the properties of Fagopyrum tataricum Gaertn starch were significant differences in nitrogen fertilizer levels, years and the interactions among nitrogen fertilizer levels and years except the pasting temperatures (Table 5), which indicated that the properties of starch were affected by different nitrogen treatments and years (Table 5).

The quality of crop is affected by many factors. For example, the structure and composition of amylose and amylopectin and the chain length distribution of amylopectin are affected by temperature variances in two years [56]. In addition, nitrogen fertilizer also has an effect on grain quality [57]. Sing et al. found that the apparent amylose content, final viscosity and setback viscosity were higher in the delayed transplanted paddy and the changes in milled rice caused by delayed transplanting of paddy might be because of cool nighttime air temperature [58], which were consistent with the results of this study. From the Table 5, the variances in temperature led to some significant changes in Fagopyrum tataricum Gaertn. Previous study reported that the amylose content was most sensitive parameter under changing environmental conditions [59].

\section{Conclusion}

With increasing nitrogen level, the starches of Fagopyrum tataricum Gaertn presented similar starch granule morphologies but lower granule sizes and higher structure complexity. The application of nitrogen fertilization increased pasting temperature, gelatinization enthalpy, light transmittance, solubility, and decreased the amylose content and retrogradation of the starch. The nitrogen level did not change the XRD patterns but increased the relative crystallinity. The result of analysis of variance indicated that nitrogen fertilization and years significantly affected the physicochemical properties of Fagopyrum tataricum Gaertn starches. Overall, the fertilization of $180 \mathrm{~kg} / \mathrm{ha}$ and $225 \mathrm{~kg} / \mathrm{ha}$ nitrogen fertilizer could obtain Fagopyrum tataricum Gaertn with desirable starch physicochemical properties.

\section{Acknowledgement}

We would like to express my gratitude to all those who helped us during the writing of this article.

\section{Conflict of Interest}

We have no conflict of interests to disclose and the manuscript has been read and approved by all named authors.

\section{References}

1. Wang X, Feng B, Xu Z, Sestili F, Zhao G, et al. (2014) Identification and characterization of granule bound starch synthase I (GBSSI) gene of tartary buckwheat (Fagopyrum tataricum Gaertn.). Gene 534(2): 229235.

2. Bojka Kump, Branka Javornik (2002) Genetic diversity and relationships among cultivated and wild accessions of tartary buckwheat (Fagopyrum tataricum Gaertn.) as revealed by RAPD markers. Genet Resour Crop Ev 49(6): 565-572.

3. Nina Fabjan, Janko Rode, Kosir IJ, Zhuanhua Wang, Z Zhang, et al. (2003) Tartary Buckwheat (Fagopyrum tataricum Gaertn.) as a Source of Dietary Rutin and Quercitrin. J Agr Food Chem 51(22): 6452-6455.

4. Qin P, Qiang W, Fang S, Hou Z, Ren G (2010) Nutritional composition and flavonoids content of flour from different buckwheat cultivars. Int J Food Sci Tech 45(5): 951-958.

5. J Gao, I Kreft, G Chao, Y Wang, X Liu, L et al. (2016) Tartary buckwheat (Fagopyrum tataricum Gaertn.) starch, a side product in functional food production, as a potential source of retrograded starch. Food Chem 190: 552- 558

6. H Liu, M Lv, Q Peng, F Shan, M Wang (2015) Physicochemical and textural properties of tartary buckwheat starch after heat-moisture treatment at different moisture levels. Starch-Starke 67(3-4): 276-284.

7. F Zhu (2016) Buckwheat starch: Structures, properties, and applications. Trends Food Sci Tech 49: 121-135.

8. KO Falade, M Semon, OS Fadairo, AO Oladunjoye KK Orou (2014) Functional and physico-chemical properties of flours and starches of African rice cultivars. Food Hydrocolloid 39: 41-50.

9. D Zhu, H Zhang, B Guo, K Xu, Q Dai, C Wei, G Zhou, Z Huo (2016) Effects of nitrogen level on structure and physicochemical properties of rice starch. Food Hydrocolloid 63: 525-532.

10. X Yang, J Bi, RG Gillbert, G Li, Z Liu, S Wang, Y Ding (2016) Amylopectin chain length distribution in grains of japonica rice as affected by nitrogen fertilizer and genotype. J Cereal Sci 71: 230-238. 
11. J Gu, J Chen, L Chen, Z Wang, H Zhang, J Yang (2015) Grain quality changes and responses to nitrogen fertilizer of japonica rice cultivars released in the Yangtze River Basin from the 1950s to 2000s. The Crop J 3(4): 285-297.

12. N Singh, N Pal, G Mahajan, S Singh, K Shevkani (2011) Rice grain and starch properties: Effects of nitrogen fertilizer application. Carbohyd Polym 86(1): 219-225.

13. PW Gous, F Warren, OW Mo, RG Gilbert, GP Fox (2015) The effects of variable nitrogen application on barley starch structure under drought stress. JI Brewing 121(4): 502-509.

14. LU Dalei, J Liquan, D Wang, Q Han, H Guo, et al. (2010) The starch pasting properties in different nitrogen topdressing treatments under spring and autumn season of waxy maize varieties. Acta Ecol Sin 30(2): 549555.

15. YL Shan, GQ Zhang, QG Luo, SW Guo, F Cao (2012) Effect of Nitrogen and Sulfur Fertilizer on Granule Size Distribution, Composition and Pasting Properties of Wheat Starch. J Triticeae Crops 32(1): 60-67.

16. D Zhu, H Zhang, B Guo, K Xu, Q Dai, et al. (2017) Effects of nitrogen level on structure and physicochemical properties of rice starch, Food Hydrocolloid. 63: 525-532.

17. Q Yang, P Zhang, Y Qu, X Gao, J Liang, P Yang, B Feng (2018) Comparison of physicochemical properties and cooking edibility of waxy and nonwaxy proso millet (Panicum miliaceum L.). Food Chem 257: 271-278

18. X Zhang, J Feng, H Wang, J Zhu, Y Zhong, et al. (2017) Bivariate flow cytometric analysis and sorting of different types of maize starch grains. Cytom Part A 93(2): 213-221.

19. LJ Zhu, QQ Liu, Y Sang, MH Gu, YC Shi (2010) Underlying reasons for waxy rice flours having different pasting properties. Food Chem. 120(1): $94-100$

20. VG Uarrota, ER Amante, IM Demiate, F Vieira, I Delgadillo, M Maraschin (2013) Physicochemical, thermal, and pasting properties of flours and starches of eight Brazilian maize landraces (Zea mays L.). Food Hydrocolloid. 30(2): 614-624.

21. G Chao, J Gao, R Liu, L Wang, C Li, et al. (2015) Starch physicochemical properties of waxy proso millet (Panicum Miliaceum L.). Starch-Starke 66(11-12): 1005-1012.

22. H Liu, X Guo, Y Li, H Li, H Fan, et al. (2016) Invitro digestibility and changes in physicochemical and textural properties of tartary buckwheat starch under high hydrostatic pressure. J Food Eng 189: 64-71.

23. HS Choi, HS Kim, CS Park, By Kim, MY Baik (2009) Ultra high pressure (UHP)-assisted acetylation of corn starch. Carbohyd Polym 78(4): 862868.

24. D Lu, X Sun, F Yan, X Wang, R Xu, et al. (2013) Effects of high temperature during grain filling under control conditions on the physicochemical properties of waxy maize flour. Carbohydrate Polymers 98(1): 302-310.

25. Y Wang, YX Song, Y Zhang, DZ Kong, Q Zhao, et al. (2017) Characteristics of starch synthesis and grain filling of common buckwheat. J Cereal Sci 73: 116-121.

26. Z Xu, L Xiao, H Li, Y Ren, Z Li (2012) Effect of Temperature on Starch Accumulation and Activities of Starch Synthetic Key Enzymes during Grain-filling Stage of Aromatic Rice. In: H Zhang, D Jin (Eds.), Intelligent Materials, Applied Mechanics and Design Science 152-156.

27. M Thitisaksakul, RC Jimenez, MC Arias, DM Beckles (2012) Effects of environmental factors on cereal starch biosynthesis and composition. ] Cereal Sci 56(1): 67-80.

28. PD Commuri, RJ Jones (2001) High temperatures during endosperm cell division in maize: A genotypic comparison under in vitro and field conditions. Crop Sci 41(4): 1122-1130.

29. J Kossmann, J Lloyd (2000) Understanding and influencing starch biochemistry. Crit Rev Plant Sci 19(3): 171-226.

30. T Umemoto, Y Nakamura, N Ishikura (1995) Activity of Starch Synthase and the Amylose Content in Rice Endosperm. Phytochem 40(6): 16131616.
31. CK Riley, AO Wheatley, I Hassan, MH Ahmad, EYSA Morrison, et al. (2004) In vitro Digestibility of Raw Starches Extracted from five Yam (Dioscorea spp.). Species Grown in Jamaica. Starch-Starke. 56(2): 69-73.

32. DB Bechtel, I Zayas, R Dempster, JD Wilson (1993) Size-distribution of starch granules isolated from hard red winter and soft red winter wheats. Cereal Chem 70(2): 238-240.

33. RN Waduge, S Xu, E Bertoft, K Seetharaman (2013) Exploring the surface morphology of developing wheat starch granules by using Atomic Force Microscopy. Starch-Starke 65(5-6): 398-409.

34. S Singh, N Singh, N Isono, T Noda (2010) Relationship of Granule Size Distribution and Amylopectin Structure with Pasting, Thermal, and Retrogradation Properties in Wheat Starch. J Agr Food Chem 58(2): 1180-1188.

35. HJ Liu, HL Yao, CY Shi, LM Zhang (2014) Effect of Potassium Application Time on Starch Accumulation and Related Enzyme Activities of Sweet Potato Variety Jixu 23. Sci Agric Sin 47(1): 43-52.

36. RF Tester I Karkalas (2001) The effects of environmental conditions on the structural features and physico-chemical properties of starches. Starch-Starke 53(10): 513-519.

37. EA Shimelis, M Meaza, SK Rakshit (2006) Physico-chemical Properties, Pasting Behavior and Functional Characteristics of Flours and Starches from Improved Bean (Phaseolus vulgaris L.) Varieties Grown in East Africa. CIGR 8(5): 1-19.

38. X Kong, P Zhu, Z Sui, J Bao (2015) Physicochemical properties of starches from diverse rice cultivars varying in apparent amylose content and gelatinisation temperature combinations. Food Chem 172: 433-440.

39. RBK Wong, J Lelievre (1982) Rheological characteristics of wheat starch pastes measured under steady shear conditions. J Appl Polym Sci 27(5): $1433-1440$.

40. B Zhu, XU Xiaojie, XU Yufeng, XU Jiefen, S Shi, Q Zhang, Y Zhang (2015) Effects of Nitrogen Application Rate on Grain Yield and Quality of Mechanical Transplant-ing Japonica Rice Wuyunjing 27. China Rice 21(5): 63-66.

41. CK Simi, TE Abraham (2008) Physicochemical Rheological and Thermal Properties of Njavara Rice (Oryza sativa) Starch. J Agr Food Chem 56(24): 12105-12113.

42.J Loh (2014) The effect of shear rate and strain on the pasting behavior of food starches. J Food Eng 16(1-2): 75-90.

43. MJ Miles, VJ Morris, PD Orford, SG Ring (1985) The roles of amylose and amylopectin in the gelation and retrogradation of starch. Int J Food Eng 135(2): 271-281.

44. W Zhang, X Liu, Q Wang, H Zhang, M Li, et al. (2018) Effects of potassium fertilization on potato starch physicochemical properties. Int J Food Sci Tech.

45. Y Ji, LM Pollak, S Duvick, K Seetharaman, PM Dixon, PJ White (2007) Gelatinization properties of starches from three successive generations of six exotic corn lines grown in two locations. Cereal Chem 81(1): 5964.

46. Przetaczek Rożnowska (2017) Physicochemical properties of starches isolated from pumpkin compared with potato and corn starches. Int J Biol Macromol 101: 536-542.

47. D Zhu, H Zhang, B Guo, K Xu, Q Dai, et al. (2016) Effect of Nitrogen Management on the Structure and Physicochemical Properties of Rice Starch. J Agr Food Chem 64(42): 8019-8025.

48. IM Park, AM Ibáñez, F Zhong, CF Shoemaker (2010) Gelatinization and Pasting Properties of Waxy and Non-waxy Rice Starches. Starch-Starke 59(8): 388-396.

49. NWH Cheetham, L Tao (1998) Variation in crystalline type with amylose content in maize starch granules: an X-ray powder diffraction study, Carbohyd. Polym 36(4): 277-284

50. R Colussi, J Singh, L Kaur, EDR Zavareze, ARG Dias et al. (2017) Singh, Microstructural characteristics and gastro-small intestinal digestion in vitro of potato starch: Effects of refrigerated storage and reheating in microwave. Food Chem 226: 171-178. 
51. R Kingcam, S Devahastin, N Chiewchan (2008) Effect of starch retrogradation on texture of potato chips produced by low-pressure superheated steam drying. J Food Eng 89(1): 72-79.

52. S Wang, C Li, L Copeland, Q Niu, S Wang (2015) Starch Retrogradation: A Comprehensive Review. Compr Rev Food Sci 14(5) 568-585.

53. RF Tester, J Karkalas (2015) The Effects of Environmental Conditions on the Structural Features and Physico-chemical Properties of Starches. Starch-Starke. 53(10): 513-519.

54. IA Adeyemi, SO Fagade, KA Ayotade (1986) Some physicochemical and cooking qualities of Nigeria rice varieties. Nigerian Food Journal 4: 2633.

55. E Chiotelli, MM Le (2002) Effect of small and large wheat starch granules on thermomechanical behavior of starch. Cereal Chem. 79(2): 286-293.
56. T Umemoto, Y Nakamura, H Satoh, K Terashima (1999) Differences in amylopectin structure between two rice varieties in relation to the effects of temperature during grain-filling. Starch-Starke 51(2-3): 58-62.

57. M Dingkuhn, PY LeGal (1996) Effect of drainage date on yield and dry matter partitioning inirrigated rice. Field Crops Res 46(1-3): 117-126.

58. N Singh, P Paul, AS Virdi, P Kaur, G Mahajan (2014) Influence of Early and Delayed Transplantation of Paddy on Physicochemical, Pasting, Cooking, Textural, and Protein Characteristics of Milled Rice. Cereal Chem 91(4): 389-397.

59. P Kaur, P Pal, AS Virdi, A Kaur, N Singh, G Mahajan (2016) Protein and starch characteristics of milled rice from different cultivars affected by transplantation date. J Food Sci Tech Mys 53(8): 3186-3196. 